\title{
A CARACTERIZAÇÃO DOS AGRICULTORES FAMILIARES QUE CULTIVAM TABACO NO TERRITÓRIO CENTRO- SUL/RS
}

\author{
THE CHARACTERIZATION OF THE FAMILY FARMERS \\ WHO GROW TOBACCO IN THE TERRITORY OF SOUTH- \\ CENTRAL/RS
}

\author{
Décio Souza Cotrim \\ Universidade Federal de Pelotas - Pelotas - RS - Brasil \\ Mario Duarte Canever \\ Universidade Federal de Pelotas - Pelotas - RS - Brasil \\ Volnei Wrusch Leitzke
}

Empresa Estadual de Assistência Técnica e Extensão Rural - Porto Alegre - RS -

Brasil

\begin{abstract}
Resumo: O cultivo de tabaco no Brasil está centrado na Região Sul e em sua ampla maioria assentado na categoria da Agricultura Familiar. Esse fato traz um conjunto de características típicas desse grupo social que ao mesmo tempo os diferencia e os aproxima. O presente artigo tem como objetivo apresentar e analisar algumas dessas características focando em agricultores do território Centro-Sul do Rio Grande do Sul RS. O método utilizado foi a construção e análise de um banco de dados baseado em entrevistas primárias realizadas pela equipe de profissionais da extensão rural. Como resultado, foi possível constatar que esses agricultores, em sua maioria, possuem uma educação formal no nível fundamental, sendo que o ensino superior e técnico não se configura como uma realidade atual. Eles estão envolvidos com o cultivo do tabaco entre 20 a 30 anos, o que produz um alto grau de conhecimento sobre o tema e um grupo de estruturas dentro da propriedade. Eles plantam, em média, trinta mil pés de fumo por safra, mas muitos utilizam a estratégia de ampliação dessa área cultivada voltando a comercialização para o mercado de "atravessadores". As famílias apresentaram de alta a altíssima dependência econômica do tabaco, porém $65 \%$ demonstraram interesse em sair da atividade.
\end{abstract}

Palavras-Chave: Diversificação Tabaco. Extensão Rural. Território 
Abstract:Tobacco cultivation in Brazil is centered in the South and in its vast majority settled in the category of Family Farming. This fact brings a set of typical characteristics of this social group that approach and differentiate them at the same time. This article aims to present and analyze some of these characteristics focusing on farmers in the territory south-center of the state of Rio Grande do Sul. The method used was the construction and analysis of a database based on primary interviews conducted by professional staff of agricultural extension. As a result, it was possible to realize that these farmers, in their majority, have a formal education in elementary level, and the higher and technical education is not configured as a current reality. They are involved with the cultivation of tobacco between twenty to thirty years, producing a high degree of knowledge on the topic and a group of structures within the property. They grow on average thirty thousand feet of tobacco per harvest, but many use the expansion strategy of this acreage back to marketing for the market "profiteers". Families showed high to very high economic dependence of tobacco cultivation, however $65 \%$ showed interest in leaving the activity.

Keywords: Diversification Tobacco. Agricultural Extension. Territory 


\section{Introdução}

O artigo aqui proposto está emerso dentro da problemática do cultivo de tabaco. Essa cadeia produtiva impacta um conjunto de territórios que estão no entorno da sede da Universidade Federal de Pelotas-UFPEL, sendo naturalmente um foco de interesse científico de um grupo de pesquisadores dessa instituição. Entre as possibilidades existentes no raio de ação da Universidade, optou-se pelo recorte do território Centro-Sul, do Estado do RS, para ser o espaço empírico para esta pesquisa.

Cabe enfatizar que a escolha do tema em estudo se sustenta pela concentração desse cultivo alocado na Região Sul, ou seja, $88 \%$ do cultivo de tabaco no Brasil estão centrados em 704 municípios do RS, SC e PR (AFUBRA, 2014).

Outro fator motivador da pesquisa é a alta importância econômica da cadeia produtiva e a peculiaridade de que a quase totalidade das unidades de produção de tabaco é categorizada como da Agricultura Familiar1. Analisando somente a safra 2014 identifica-se que foram plantados 323 mil hectares de tabaco, produzindo 731 mil toneladas, gerando trabalho para 162 mil famílias de agricultores e constituindo um rendimento de $R \$ 5,3$ bilhões (AFUBRA, 2014).

Essa cadeia produtiva está alicerçada em um Sistema Integrado de Produção de Tabaco-SIPT, no qual as empresas integradoras fornecem aos agricultores um pacote composto de crédito, sementes, agrotóxicos e orientação técnica provendo a garantia de aquisição da safra. Segundo Vargas e Oliveira (2010), o SIPT cresce no sul do Brasil em razão do baixo custo de produção e da alta qualidade do tabaco produzido. Esses autores apontam que os agricultores que cultivam tabaco enfatizam que as principais vantagens do cultivo são a garantia da compra da safra e o alto preço do quilograma do fumo comparativamente a outras alternativas agropecuárias ( $R \$ 7,30 /$ quilo na safra 2014). Em outra perspectiva, Cotrim (2013) balizou que um grande número de agricultores familiares sonha em abandonar o tabaco em razão do excessivo trabalho exigido pelo cultivo, da alta penosidade, em especial das fases de colheita e secagem, e do uso intensivo de venenos que

\footnotetext{
'Dentro desse artigo, de forma normativa, entende-se Agricultura Familiar conforme o arcabouço da Lei $n^{\circ} 11.326$, de 24 de julho de 2006 (BRASIL, 2006).
} 
afetam a saúde das famílias. Esse fato gera um paradoxo no interior das famílias dos agricultores entre as vantagens econômicas do cultivo e os altos custos sociais e ambientais.

Abrindo para um contexto mundial, o tabaco passa por uma crise. A sociedade civil entende que o vício do cigarro traz malefícios a um conjunto expressivo de pessoas. Nesse movimento, em 2003, emerge o tratado internacional intitulado Convenção Quadro de Controle do Fumo-CQCF, assinada por 191 países, que propõe ações de redução da demanda e consumo de cigarro. O Brasil é signatário da convenção desde 2005 (BRASIL, 2010).

Nessa trajetória, o governo federal busca a criação de políticas públicas que visem à redução do plantio de tabaco por meio da oferta de alternativas aos agricultores. Como uma das ações, o Ministério do Desenvolvimento Agrário-MDA lançou, em 2013, uma Chamada Pública para seleção de Assistência Técnica e Extensão Rural-ATER, que objetiva a contratação de ATER para contemplar medidas educativas de diversificação de cultivos e criações, dentro do âmbito da CQCF, que sejam sustentáveis e que promovam a organização da comercialização, ou seja, um procedimento de diversificação assentado em um amplo processo de Desenvolvimento Rural (BRASIL, 2013).

Dentro das regiões atingidas pela Chamada Pública está o território Centro-Sul/RS, localizado no eixo entre as cidades polos de Pelotas e Porto Alegre (BRASIL, 2009). Nesse território, foi contratada assistência técnica para 960 famílias de agricultores que cultivam tabaco dentro dos municípios de Dom Feliciano, Chuvisca, Camaquã, Cerro Grande do Sul, Barão do Triunfo, São Jerônimo e General Câmara (BRASIL, 2013).

A instituição de ATER vencedora da Chamada Publica para o território Centro Sul foi a Emater/RS, que executa o serviço oficial de extensão rural do Estado do RS. O grupo técnico responsável é formado por 15 profissionais, sendo contratada para a realização de um diagnóstico inicial das unidades de produção, dinamização social do processo de organização comunitária, construção coletiva com os agricultores das alternativas ao tabaco e implantação de unidades de referência dessas alternativas com o intuito de espalhar essa ideia entre os agricultores. Esse processo de extensão rural, dentro da Chamada Pública, deve estar pautado em princípios participativos e educativos. 
O diagnóstico inicial da unidade de produção foi uma ação desenvolvida pela equipe de extensionistas diretamente nas 960 propriedades dos agricultores familiares por meio de uma entrevista estruturada, no intuito de produzir um conjunto de informações centrais para o entendimento do modo de vida e de produção no território Centro Sul.

O diagnóstico inicial foi composto por 12 dimensões analíticas que possuem um entrelaçamento entre as informações. Foram levantados dados básicos da família dos agricultores, como identificação, localização, composição familiar e descendência étnica. Dados da participação social da família em associações, cooperativas, sindicatos e outros. Foi caracterizado o domicilio familiar por meio dos dados referentes à luz, à água, ao esgoto, ao lixo, ao acesso à saúde, às facilidades de transporte, ao acesso informação e à educação. Do ponto de vista da produção agropecuária, foi questionada a caracterização fundiária das propriedades, o uso da terra, característica da benfeitoria e maquinário e composição do rebanho. Também foi enfatizada a descrição do sistema de produção do tabaco, o manejo de solo e água e prospectado as perspectivas de cultivos e criações para diversificação. Finalizando foram levantadas informações referentes à saúde no trabalho, ao acesso ATER, à produção para o autoconsumo familiar e ao cálculo da renda bruta familiar. Ou seja, um amplo conjunto de informações que permite uma descrição pormenorizada de várias dimensões analíticas de um amplo conjunto de famílias de agricultores familiares em um dado território.

Esse diagnóstico inicial propiciou aos extensionistas começarem o trabalho de construção de alternativas ao tabaco em ações participativas dentro das comunidades rurais. Porém, cabe enfatizar que os dados levantados permitem um conjunto maior de análises e estudos em relação à problemática do tabaco. O grupo de informações diagnosticado é amplo e inter-relacionado, que permite a construção de análises preciosas para $\mathrm{o}$ entendimento da complexidade das estratégias de reprodução social dessas famílias. Nesse ponto, emerge a parceria entre a UFPEL/Faculdade de Agronomia Eliseu MacielFAEM/Núcleo de Estudo em Agroenegócio-NEA e a Emater/RS para a continuidade dos estudos por meio do conjunto das informações sistematizadas. 
A UFPEL, em uma primeira etapa da pesquisa, transformou o diagnóstico em um banco de dados para a exploração científica por professores, alunos de mestrado/doutorado e alunos de graduação na intenção de gerar conhecimento científico que possa ser aportado na qualificação da ação da extensão rural e na melhoria da qualidade de vida das famílias rurais.

Os estudos desse banco de dados, iniciado em 2015, estão em sua primeira etapa, mostrando promissores indicativos. Neste contexto, este artigo é o primeiro produto acadêmico desse esforço de pesquisa, tendo como objetivo principal produzir uma caracterização dos elementos centrais do grupo de agricultores familiares que cultivam tabaco buscando delimitar os grandes contornos que os identificam, e também, os primeiros insights produzidos a partir da análise dos dados.

\section{Metodologia}

A pesquisa teve seu ponto inicial na confecção do diagnóstico inicial produzido pala equipe de ATER da Emater/RS. Foram realizadas visitas individuais a cada um dos 960 agricultores familiares e desenvolvido um roteiro de entrevista que consumiu aproximadamente quatro horas. $O$ desenho do roteiro de entrevista foi padronizado por formulário.

Esse tipo de entrevista permitiu uma conversa informal entre pesquisador e entrevistado, balizada por um conjunto de temas prédefinidos no qual foi explorado um conjugado de pontos de interesse sobre o assunto (BONI; QUARESMA, 2005).

O conjunto de dados obtido constituiu um corpus muito grande. O diagnóstico atinge um conjunto de 12 dimensões analíticas que passam por dados sociais amplos, produção agropecuária e centram foco no tabaco e as possibilidades de diversificação. Cabe lembrar também que a amostra é bastante ampla, com 960 entrevistas.

Essa massa de dados foi sistematizada e codificada pela equipe da UFPEL, construindo um banco de dados para utilização dentro do programa Statistical Package for the Social Sciences - SPSS, que permite a análise de inúmeras combinações de dados gerando informações voltadas à análise científica. Uma parcela inicial dos insights obtidos no processo será apresentada neste artigo, atendendo o objetivo de 
produzir a caracterização dos elementos centrais dos agricultores familiares que cultivam tabaco.

Também foi realizada uma entrevista coletiva com os extensionistas da Emater/RS para a captação das percepções qualitativas dos profissionais que realizaram o diagnóstico. Essa entrevista foi efetivada no formato grupal apoiada por perguntas orientadoras. A condução da dinâmica e a sistematização das informações foram realizadas pelos pesquisadores da UFPEL com uso de tarjetas e visualização móvel (VERDEJO, 2006). 


\section{Resultados e Discussões}

Essa seção do artigo está dividida em uma primeira etapa que contextualiza o cultivo de tabaco no território Centro-Sul do RS e uma etapa final que apresenta dados sistematizados oriundos do banco de dados e analisa os elementos centrais que o caracterizam.

Bases agronômicas na produção de tabaco

Os dados que serão inicialmente apresentados buscam criar um pano de fundo para o entendimento da dinâmica do cultivo de tabaco no espaço empírico que estamos estudando. São frutos da entrevista coletiva com os extensionistas da Emater/RS que realizaram a pesquisa de campo e diálogo com as referências teóricas.

O cultivo do tabaco iniciou no território Centro-Sul no começo da década de 70. O pacote tecnológico do tabaco foi colocado aos agricultores dentro do bojo do processo de modernização da agricultura² (ROSIAK, 2008). O sistema de produção foi construído a partir das bases tecnológicas modernas, ou seja, lavração e gradeação dos solos, o uso de adubos químicos e corretivos e aplicação de agrotóxicos. A apropriação das bases técnicas de produção do tabaco imbricou um novo cultivo, um pacote tecnológico e outro modelo de relação com o mercado (COTRIM,2013).

O cultivo do tabaco possui fortes características de cultivos olerícolas, que exigem um amplo leque de operações manuais em todo o seu ciclo vegetativo. O sistema de cultivo do tabaco inicia no inverno, junho ou julho, pela constituição de uma sementeira para a preparação das mudas. Normalmente, são utilizadas pequenas estufas plásticas, onde são depositadas bandejas de isopor para sustentarem o crescimento dessas mudas.

Após um período médio de 60 dias, a muda é transplantada para o canteiro definitivo onde se desenvolverá. Essa área de terra é previamente preparada. A escolha das áreas para as lavouras segue a mesma lógica dos cultivos tradicionais, priorizando locais de recente

\footnotetext{
2 O processo de modernização da agricultura se caracteriza pela substituição da base técnica da agricultura. As tecnologias modernas são centradas em maquinário agrícola, insumos químicos (adubos minerais e agrotóxicos) e sementes geneticamente melhoradas.
} 
desmatamento (coivara) ou campos que ficaram em pousio, com pastagens, por período longo. Nessas áreas são plantadas, em média, 15 a 16,5 mil mudas de tabaco em um hectare. O módulo mínimo de cultivo por propriedade rural é normalmente de dois hectares.

Os solos são naturalmente propensos à erosão em razão das condições geomorfológicas e ao uso agrícola, o que propicia o entendimento pelos agricultores de que existe grande perda de solos. A paisagem do território Centro-Sul aponta para grandes áreas cobertas com floresta nativa em regeneração, em especial, nas áreas mais íngremes que abrigam os solos com alto grau de pedregosidade. No passado, essas áreas foram ocupadas com os cultivos anuais, como milho e feijão, devido à necessidade do aproveitamento total das propriedades rurais.

A troca do sistema de produção dos cultivos anuais para o tabaco propiciou a redução do uso dessas áreas. Esse fato ocorreu pela baixa pressão sobre o uso dos solos, ou seja, os agricultores desenvolvem suas lavouras de tabaco nas áreas preferências, mais planas e com acesso facilitado e planejam o restante das áreas de suas propriedades, conforme uma melhor aptidão dos solos.

Continuando a análise do ciclo do cultivo, no período do desenvolvimento vegetativo existe uma série de práticas culturais com uso de insumos modernos, como adubos químicos e agrotóxicos, que são realizadas para o aceleramento do crescimento da planta, evitar o seu florescimento, o controle de ervas invasoras, entre outros. Analisando os princípios ativos dos agrotóxicos utilizados, é perceptível que eles, em sua grande maioria, pertencem à classe toxicológica III (mediamente tóxico e classificação ambiental) e II (produto muito perigoso ao meio ambiente). A manipulação dos venenos é apontada pelos agricultores como sendo um dos grandes problemas da lavoura do tabaco (COTRIM, 2013).

O balanceamento entre área plantada e estrutura de secagem é central dentro desse sistema de produção. $O$ ajuste do dimensionamento de área de fumo a ser plantada pela família é necessário para a utilização de uma estufa para secagem das folhas.

A colheita das folhas do fumo é realizada em três etapas, iniciando, em dezembro, pelas folhas da parte de baixo das plantas e progressivamente até as folhas da ponta. A fase da colheita exige muito 
tempo, sendo o ponto máximo da utilização da mão de obra familiar. O período do verão, em especial entre os meses de janeiro a março, é o momento de estrangulamento do uso da mão de obra familiar e também de grande dificuldade de contratação de outras pessoas para o apoio na colheita.

O tabaco é comercializado seco, enfardado em arrobas, ou seja, em fardos de 15 quilos. A secagem das folhas de fumo é uma atividade obrigatória nesse sistema de produção, sendo necessária a construção nas propriedades rurais de estufas. Essas são estruturas de alvenaria de grande porte e que utilizam lenha na produção de ar quente para secagem. $\mathrm{O}$ investimento financeiro nesse equipamento é considerado alto.

A primeira tecnologia de secagem utilizada pelas estufas é a convencional, onde existem cinco andares de andainas para colocação de folhas de fumo, as quais são amarradas em varas de madeira. Nessa construção, circula naturalmente o ar quente que é gerado em uma fornalha que queima madeira. $O$ tempo de secagem é longo, gerando um produto final de boa qualidade. A necessidade de tecer as folhas de fumo nas varas de secagem e o maior tempo para a secagem resulta em um maior envolvimento em tempo dos agricultores.

\section{Figura 1. Secagem do fumo}

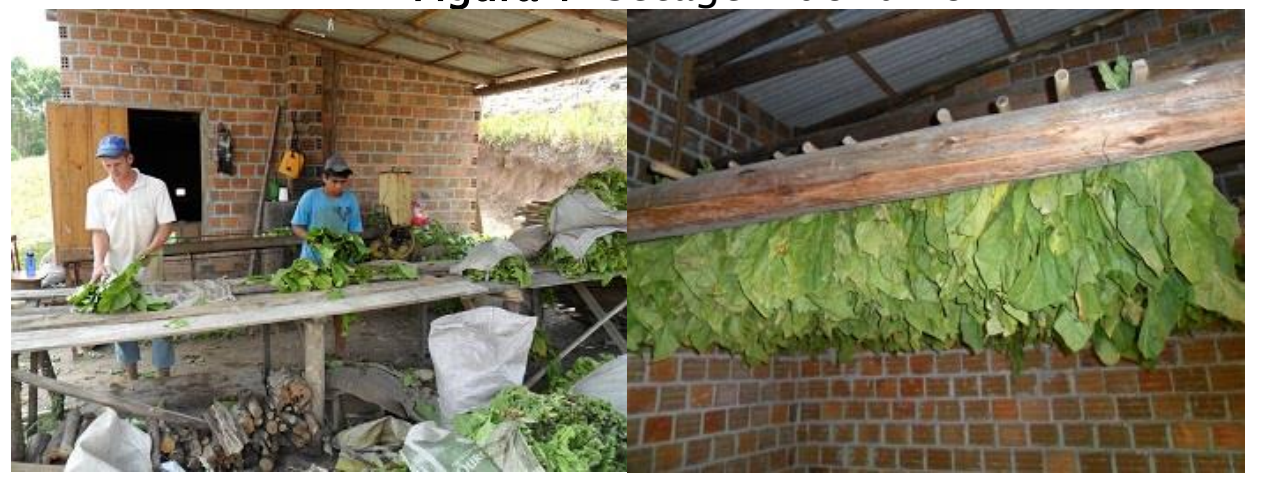

Estufa convencional de secagem de tabaco. À esquerda, agricultores na preparação do produto para secagem. À direita, visão interna da estufa com varas colocadas nas andainas dentro da estufa convencional. Comunidade Faxinal, Dom Feliciano, 2013.

A segunda e terceira geração de tecnologia de secagem são as estufas de ar forçado que foram introduzidas a partir dos anos 2000. Nessa construção, as folhas de fumo são colocadas em mesas e utilizam grampos para fixação, sem a necessidade de tecer em varas, o que 
reduz a mão de obra. $\mathrm{O}$ ar quente gerado em uma fornalha é forçado para dentro da estufa por meio de uma ventoinha. Essas estufas possibilitam a secagem de uma maior quantidade de folhas de fumo por unidade de tempo, reduzindo o uso de mão de obra. Porém, a qualidade final do produto é inferior às estufas convencionais.

Para a secagem de 30 a 35 mil pés de tabaco, que é uma safra completa de uma estufa, são consumidos de 35 a 50 metros estéreis de lenha, ou seja, entre 1 a 1,5 metros estéreis para cada 1.000 pés de fumo. $\mathrm{Na}$ atualidade, as empresas fumageiras e os órgãos de fiscalização ambiental são rígidos no controle do uso de mata nativa como lenha de secagem de fumo. Emerge a necessidade do cultivo de florestas plantadas na propriedade rural, normalmente eucalipto, para serem usados na queima das fornalhas.

Após a secagem das folhas de fumo, existe a necessidade da formação de lotes homogêneos de folhas e o enfardamento em arrobas. Essa atividade é realizada após a secagem da quase totalidade da safra e consome ainda mais tempo das famílias de agricultores.

No intuito da explicitação de todas as etapas do cultivo do tabaco, foi construído coletivamente pelos extensionistas um Calendário Sazonal3.

\footnotetext{
${ }^{3}$ Calendário Sazonal é uma ferramenta participativa de explicitação do ciclo produtivos de cultivos e criações. Ver: Verdejo (2006).
} 
Quadro 1. Calendário Sazonal Tabaco Território Centro-Sul

\begin{tabular}{|c|c|c|c|c|c|c|c|c|c|c|c|c|}
\hline \multicolumn{13}{|c|}{ Calendário Sazonal do cultivo do Tabaco } \\
\hline & $J$ & $\mathrm{~F}$ & M & A & M & $J$ & $J$ & A & $S$ & $\mathrm{O}$ & $\mathrm{N}$ & $\mathrm{D}$ \\
\hline \multicolumn{13}{|l|}{$\begin{array}{l}\text { Cultivo de solo convencional } \\
\text { (Aração, Gradagem, Canteiros) }\end{array}$} \\
\hline \multicolumn{13}{|l|}{$\begin{array}{l}\text { Plantio Direto: Semeadura de } \\
\text { aveia, nabo e ervilhaca. }\end{array}$} \\
\hline \multicolumn{13}{|l|}{$\begin{array}{l}\text { Dessecação das plantas de } \\
\text { cobertura solo }\end{array}$} \\
\hline \multicolumn{13}{|l|}{$\begin{array}{l}\text { Mudas: semeadura em sistema } \\
\text { Flothing }\end{array}$} \\
\hline \multicolumn{13}{|l|}{ Mudas: Transplante } \\
\hline \multicolumn{13}{|l|}{$\begin{array}{l}\text { Tratos Culturais: adubação } \\
\text { nitrogenada, capina, amontoa }\end{array}$} \\
\hline \multicolumn{13}{|l|}{$\begin{array}{l}\text { Tratos Culturais: Desponte e } \\
\text { aplicação de anti-brotante. }\end{array}$} \\
\hline \multicolumn{13}{|l|}{$\begin{array}{l}\text { Colheita (maior concentração de } \\
\text { trabalho) }\end{array}$} \\
\hline \multicolumn{13}{|l|}{ Cura das folhas e secagem } \\
\hline $\begin{array}{l}\text { Classificação, enfardamento e } \\
\text { comercialização. }\end{array}$ & & & & & & & & & & & & \\
\hline
\end{tabular}

Fonte: elaborado pelos autores

O cultivo de tabaco possui atividades na totalidade do ano. Os meses entre janeiro e março são os de maior concentração de uso da força de trabalho da família, pois se acoplam às atividades de colheita e secagem.

Nos casos dos agricultores que plantaram áreas maiores que sua estrutura familiar comporta, esses necessitam lançar mão da contratação de diaristas, chamados de peões, que possuem um alto custo diário e são de difícil localização nas fases de maior demanda de mão de obra, em especial nos meses de verão.

Dentro do SIPT, há volatilidade de preços dependendo da oferta e demanda supra anual. Assim, preços altos em uma determinada safra estimulam os agricultores a realizarem vantagens econômicas naqueles períodos. Contudo, muitas vezes, essa estratégia fracassa em virtude da impossibilidade de otimizar estrutura física, mão de obra e outros fatores produtivos que são relativamente fixos no curto-médio prazo com o aumento da produção desejada. Essa estratégia tende a gerar como resultado uma ampliação das dificuldades de administração 
interna, uma crise financeira e a consequente perda dos contratos com as empresas fumageiras.

O custo com empregado rural pode consumir boa parte do lucro da atividade, deixando o agricultor a mercê fundamentalmente do preço pago pelo produto final. Os agricultores entendem essa lógica e tendem a ajustar o tamanho das suas áreas, fortemente influenciados pela disponibilidade de mãos familiares para o trabalho.

Os agrotóxicos são de uso cotidiano na lavoura de tabaco, principalmente os herbicidas e antibrotantes. Os agricultores percebem que esses produtos químicos são venenos que prejudicam a sua saúde e a do meio ambiente. O veneno não é aceito como normal ou necessário. Esse é entendido como algo errado que está sendo usado, ou seja, ele não é aceitável pelo grupo social. Em algumas famílias, quando se vai usar o veneno no tabaco, se proíbe-se a presença das crianças na lavoura, em uma tentativa de preservar os mais jovens.

Outras complicações em relação à saúde das pessoas começaram a serem percebidas pelos órgãos de saúde pública. Existe uma preocupação empírica de que o trabalho junto ao tabaco e a exposição aos agrotóxicos possam causar um aumento na população dos agricultores, de doenças como a depressão e o câncer. Um grupo de profissionais ligados ao Ministério da Saúde está pesquisando a manifestação da "doença da folha verde do tabaco". Essa se revela por meio de náuseas, vômito e fraqueza geral, sendo uma intoxicação aguda causada pela absorção dérmica da nicotina da folha do fumo. $O$ primeiro relato dessa doença no Brasil foi descrito no Rio Grande do Sul em 2007 (OLIVEIRA, 2010). Essa intoxicação por nicotina ocorre pelo contato direto com a planta de tabaco, em especial na fase de colheita. Esse é um fator que prejudica a saúde de todos os agricultores envolvidos com esse tipo de trabalho.

Caracterização e análise dos elementos centrais do grupo de agricultores familiares que cultivam tabaco

Nesse tópico, serão apresentados alguns quadros com resultados sistematizados do banco de dados, desenvolvidos a partir das entrevistas com os agricultores que cultivam tabaco, e analisados os elementos centrais. 
Dentro dos dados básicos da estrutura familiar optou-se pela análise da escala de escolaridade dos agricultores pertencentes ao grupo das famílias que cultivam tabaco. Esse dado possibilita a visualização do tempo que cada elemento da família permaneceu dentro da escola formal.

A educação formal ${ }^{4}$, nesse contexto, é considerada um bom indicador para análise da apreensão de ferramentas que serão úteis na construção das estratégias de reprodução social da agricultura familiar. Acredita-se na hipótese que um agricultor com maior número de anos na escola conseguirá captar um ferramental mais amplo e diversificado, que o auxiliará nas atividades profissionais e na própria vida social (OLIVEIRA, 2007).

A escala do indicador utilizada no quadro foi de "analfabeto" para aquele que não sabe ler e escrever; "ensino fundamental incompleto", com menos de 8 anos de escola formal; "ensino fundamental completo", com 8 anos de escola formal; "ensino médio incompleto", com menos que 11 anos de escola formal; "ensino médio completo", com 11 anos de escola formal; "ensino técnico", durante ensino médio realizou curso de cunho técnico; "ensino superior incompleto", cursou faculdade e não terminou curso; "ensino superior completo" obteve diplomação em faculdade. Na sequência, é apresentado o gráfico 1 .

${ }^{4}$ Entende-se por educação formal como aquela que acontece na escola mediante a participação do professor e que tem os objetivos relativos ao ensino e a aprendizagem de conteúdos historicamente sistematizado, regimentados por leis (GOHN, 2006). 


\section{Gráfico 1. Dispersão do grau de escolaridade dos agricultores}

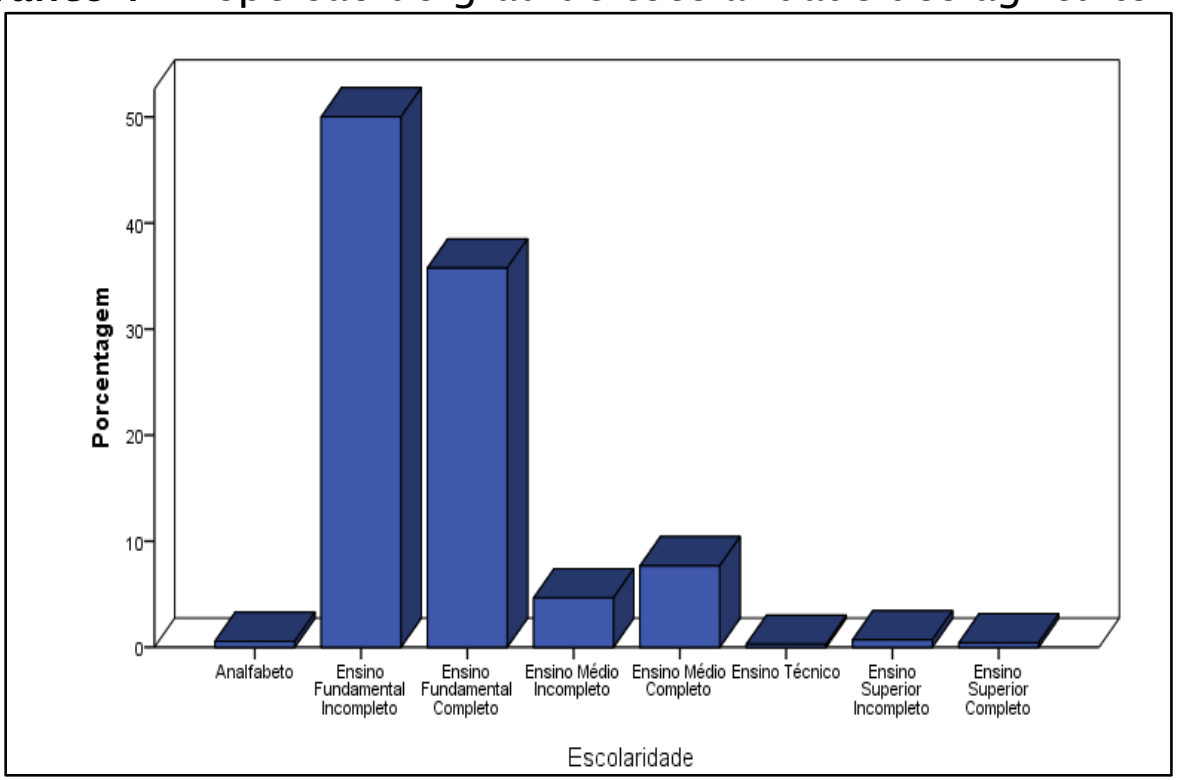

Fonte: elaborado pelos autores

Nesse gráfico, o dado que "salta aos olhos" é a concentração de agricultores com ensino fundamental incompleto (50\%) e ensino fundamental completo $(35,8 \%)$. A soma dessas duas parcelas chega a $85,8 \%$ da amostra. Outra pesquisa similar realizada pela Associação dos Fumicultores do Brasil-AFUBRA, entre os seus associados do Rio Grande do Sul, mostrou que a média de permanência na escola formal é de sete anos e que $89,9 \%$ dos agricultores têm ensino fundamental incompleto (AFUBRA, 2014). Esses dados convergem nas duas pesquisas.

No território Centro-Sul, a oferta de ensino formal no espaço rural dos municípios é ampla até o final do ensino fundamental. Porém, o ensino médio normalmente é oferecido em escola centrais das maiores comunidades ou na sede do município. A dificuldade de aceso devido à falta de transporte ou tempo diário necessário para deslocamento podem ser indícios para as explicações dos baixos índices de formação acima do ensino fundamental.

Também não existe a presença de escolas técnicas rurais nos municípios do território Centro-Sul e a oferta de faculdade está centrada apenas nas cidades maiores, como Camaquã e Tapes. Esse fator é central na explicação da presença de apenas $0,3 \%$ de técnicos e $1,1 \%$ no nível superior entre formado e incompleto. $O$ ensino superior não é uma realidade para esses agricultores.

Esse conjunto de fatos apresentados indica que o perfil do agricultor familiar que cultiva tabaco é ter uma formação em nível 
fundamental. Por um lado, esse dado extrapola a ideia do senso comum de que os agricultores são analfabetos ou com pouquíssimos anos de escola. Por outro lado, os dados apontam a presença de condicionantes que limitam a ampla oferta de oportunidades para o acesso à educação. Mesmo com a qualificação histórica dos meios de transporte e de comunicação, a distância física dentro do espaço rural ainda se caracteriza como um elemento dificultador à ampliação da educação formal e pode se tornar um limitador do desenvolvimento das famílias.

Esses agricultores tenderam a angariar na escola um ferramental com características mais operacionais. Esse fato pode auxiliar a explicar a grande penetração do SIPT nos sistemas de produção dessas famílias, visto que o cultivo de tabaco é oferecido como um pacote tecnológico fechado, com atividades bem definidas e rotinas operacionais específicas.

Analisando em outra direção, a concentração na formação fundamental pode gerar lapsos quando esses agricultores forem defrontados com problemas mais complexos, como as estruturações de novos mercados ou troca de sistemas de produção, como no caso da construção de alternativas de cultivos e criações na diversificação do tabaco. Ou seja, a educação formal apenas no nível fundamental pode ser o fator que não permite aos agricultores angariarem as perspectivas de novos horizontes no que tange aos processos de diversificação do tabaco. Esse se caracteriza como um elemento fundamental que pode dificultar os processos de transição do tabaco.

Finalizando esse aspecto, cabe salientar ainda que o território Centro Sul espelha um esforço realizado há aproximadamente dez anos para eliminação do analfabetismo rural no RS. Foram constituídos projetos de educação de adultos (MOVA, EJA) nos espaços rurais, o que produziu a redução dos índices. A existência de apenas 0,5\% de analfabetos na pesquisa atesta essa situação, sendo que somente os mais idosos permanecem nessa condição.

Continuando a análise de outros dados da pesquisa, averiguou-se que, segundo Rosiak (2008), o tabaco chegou no território Centro-Sul no início da década de 1970 no bojo do processo de "modernização da agricultura". O cultivo trouxe características de forte aplicação de insumos modernos e alto grau de intensificação no uso do solo e mão de obra dos agricultores. O plantio de tabaco teve uma rápida expansão 
impulsionada pelo apelo das suas vantagens econômicas em relação às criações e cultivos coloniais.

O Gráfico 2, apresentado na sequência, é a consolidação da pergunta: Há quantos anos a família planta tabaco?

Gráfico 2. Anos de cultivo de tabaco

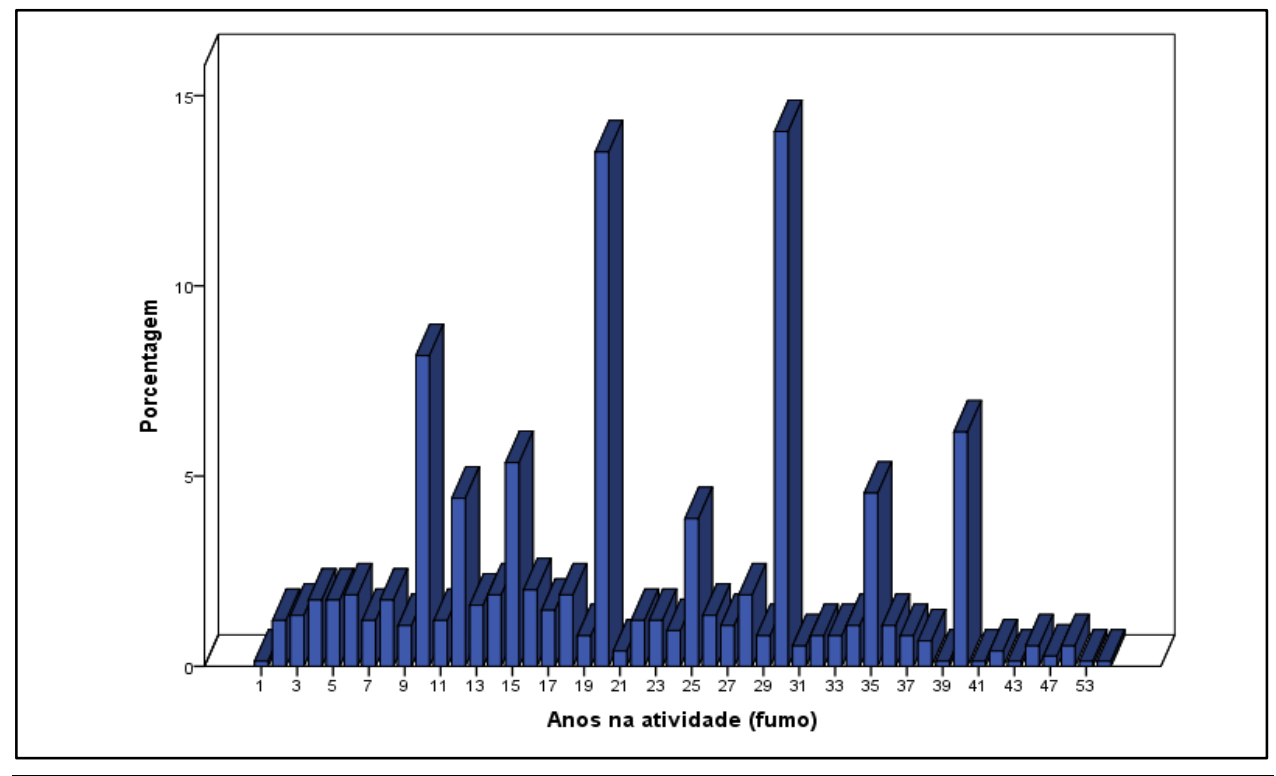

Fonte: elaborado pelos autores

A observação do Gráfico 2 permite ver uma tendência das respostas das entrevistas centradas em números redondos, ou seja, dez anos (8,2\%), 20 anos (13,5\%), 30 anos (14\%) e 40 anos (6,1\%). Esse comportamento está ligado ao formato da pergunta que não exige o preciosismo por parte do entrevistado.

O comportamento dos dados se assemelha a uma curva normal de distribuição, com médias entre 20 a 30 anos, e dados semelhantes de 10 anos, a montante, e 40 anos, a jusante. Esse fato atesta o amplo tempo de convivência dos agricultores com o tabaco. Fica patente que os agricultores que cultivam tabaco no território Centro-Sul não são iniciantes na atividade. Eles possuem uma experiência sólida na condução do cultivo e conhecimento das variações do sistema de produção.

Uma das características do SIPT é o atrelamento dos agricultores com a empresa fumageira mediante de contratos. Para a viabilização desse, é exigido um investimento inicial volumoso que é a construção da estufa de secagem. A estufa, algumas vezes, é financiada pelas 
empresas, com pagamento na colheita, porém, muitas vezes, sai da reserva dos agricultores. Essa estrutura somente tem utilidade para o cultivo de tabaco, pois nenhum outro cultivo ou criação, na atualidade, nesse território, exige secagem. Esse conjunto de fatos produz uma tendência à fidelização dos agricultores ao cultivo, ou seja, mesmo trocando de contratos, por vezes, de empresa fumageira, permanecem plantando fumo por longos períodos. Esse fato se observa na distribuição por todo período de 40 anos de percentuais de agricultores.

Saltando para uma dimensão mais agronômica dos dados, observa-se que o tabaco possui um dimensionamento regrado pela quantidade de plantas cultivadas. O padrão para o plantio são múltiplos próximos de 15 mil plantas, o que equivale aproximadamente a um hectare cultivado. O Gráfico 3, apresentado na sequência, é a consolidação da pergunta: Qual a quantidade de fumo plantado na última safra?

Gráfico 3. Quantidade de tabaco plantada última safra

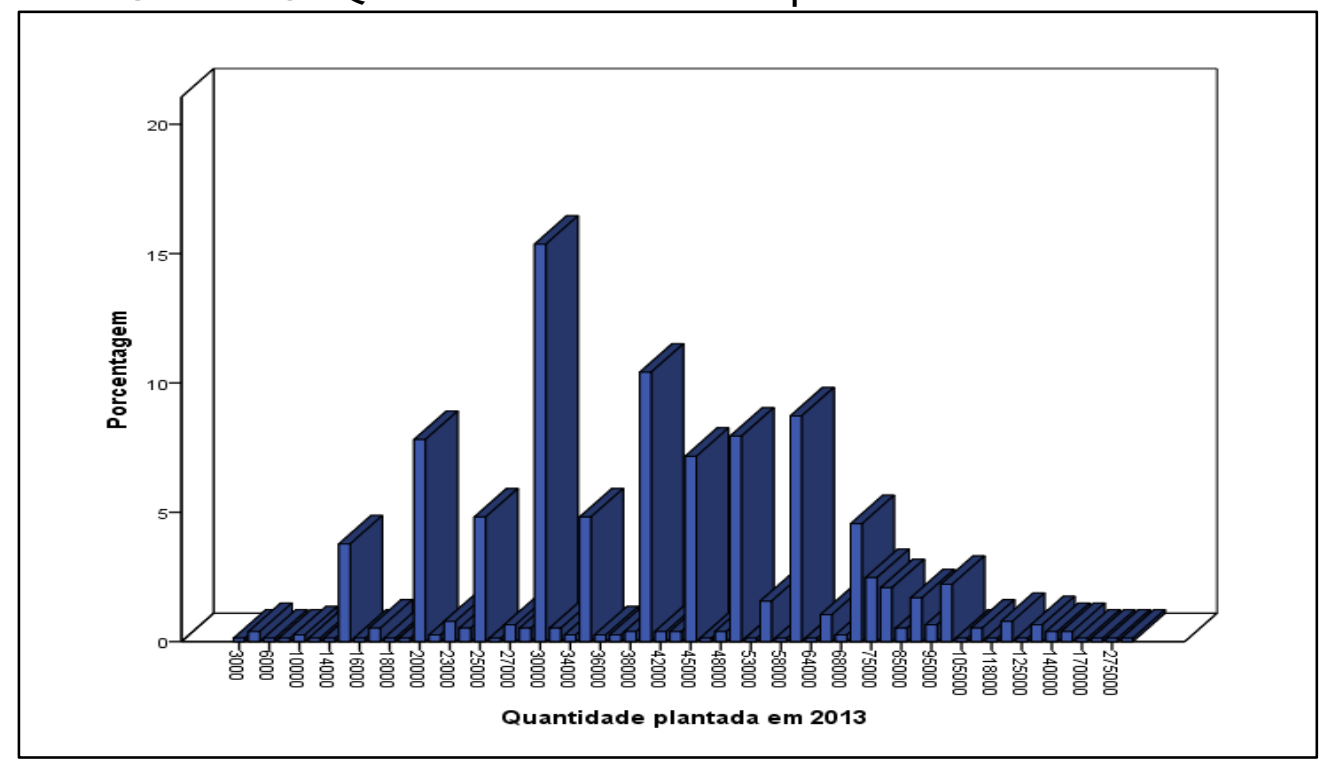

Fonte: elaborado pelos autores

Na observação da dispersão dos dados novamente se atesta um comportamento representado por uma curva normal de distribuição, em que a média recaiu sobre 30 mil plantas ( 2 ha) com 14,6\% e tem como pontos de referência, a montante, 15 mil plantas ( $1 \mathrm{ha}$ ) com 3,8\% e, a jusante, 60 mil plantas (4 ha) com 9,3\%.

É perceptível também um deslocamento da curva para a jusante. Entre 30 mil e 60 mil plantas estão alocados 33,4\% dos agricultores. 
Esse fato se explica pelo balanceamento entre a quantidade plantada e a capacidade instalada de estufas de secagem. Para o suprimento ideal de uma estufa modelo padrão, são necessárias em torno de 30 mil plantas. Porém, como observado anteriormente nos dados, os agricultores dessa região possuem uma longa trajetória de plantio de tabaco, o que gera uma tendência de possuírem uma estufa nova, de poucos anos de uso e mais eficiente, e uma ou mais estufas velhas, com capacidade inferior de secagem, mas que ainda são utilizadas em momentos de pico da safra.

Os agricultores utilizam como estratégia ampliar o número de pés plantados para $40 \mathrm{mil}$ a $50 \mathrm{mil}$ e trabalham com sobrecarga na secagem, lançando mão das estruturas de secagem antigas. Naturalmente, esse fato tem que conciliar a existência de mão de obra familiar para a colheita que é a etapa de maior demanda.

Essa estratégia permite que os agricultores cumpram os contratos com as empresas fumageiras, normalmente de um módulo de 30 mil pés, e ainda possuam uma produção livre para buscar negócios entre os atravessadores $^{5}$ de fumo da região. Essa tática aposta em anos de escassez de tabaco e elevação do preço, mas é refém de anos de safras plenas, o que provoca achatamento dos preços e, por vezes, o não pagamento dos custos de produção.

Um dado importante para a compreensão da lógica das famílias que cultivam tabaco são as informações de ordem econômica. Neste trabalho, optou-se pela apresentação e análise da importância da renda oriunda do tabaco em relação ao orçamento familiar, ou seja, a resposta da pergunta: Quanto o fumo representa do orçamento familiar?

Gráfico 4. Renda fumo impacto no orçamento familiar

${ }^{5}$ Compradores independentes de tabaco que atuam no território. 


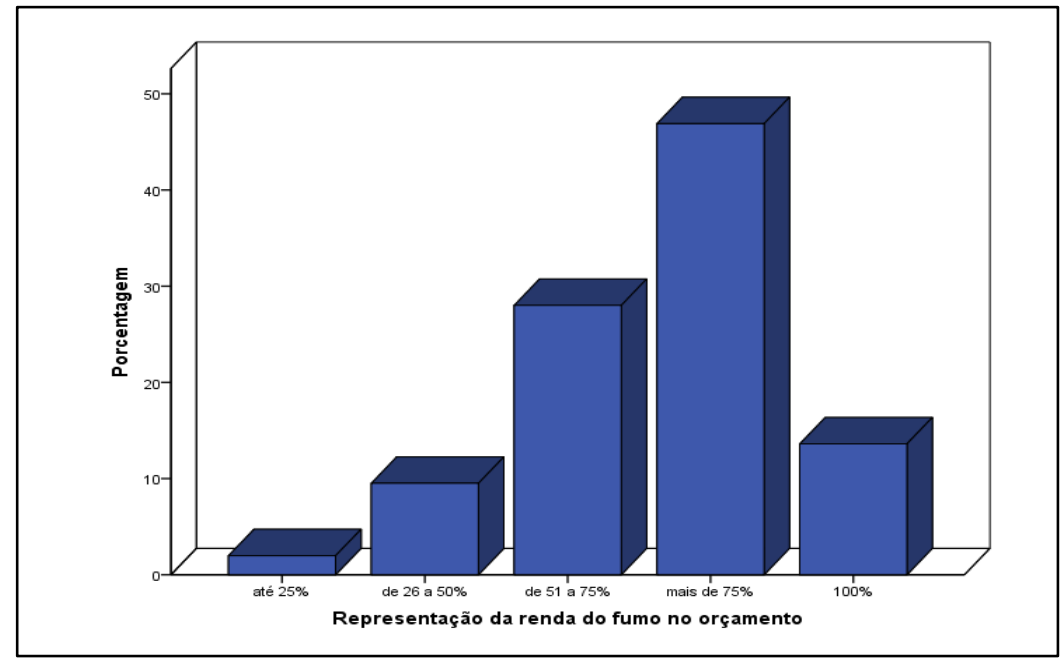

Fonte: elaborado pelos autores

O cultivo de tabaco ocupa pouca área de terra em relação à totalidade da propriedade. Com base nos dados do Gráfico 3, e considerando que as propriedades do território Centro-Sul têm, em média, 20 hectares de área total (IBGE, 2006), o fumo ocupa somente de entre 2 a 3 hectares, ou seja, 10 a 15\% da área. Esse elemento aponta para a disponibilidade de terra para desenvolvimento de um conjunto de outros cultivos e criações.

Porém, conforme o calendário sazonal apresentado no Quadro 1, o tabaco gera um alto grau de comprometimento da mão de obra familiar durante a totalidade do ano, com sobrecarga no verão, no momento da colheita. Cabe salientar também que o SIPT produz uma relação contratual entre o agricultor e a empresa fumageira. Essa convenção suscita um conjunto de obrigações por partes dos agricultores em relação ao volume a ser entregue para indústria e a qualidade do produto. $O$ desrespeito aos contratos gera sanções que dificultam futuras negociações.

Em uma análise mais ampla, pode-se afirmar que esses fatores limitam as famílias a construírem um sistema de produção com policultivos, mesmo possuindo espaço de terra. Naturalmente, esse processo leva a uma concentração no plantio de fumo e a ampliação da dependência de um único cultivo.

Esse aspecto fica patente no Gráfico 5 , onde se pode observar duas tendências das famílias entrevistadas. Existe um grupo, formado por $25,7 \%$ das famílias, com alto grau de dependência do tabaco que representa entre 50 a $75 \%$ do orçamento familiar. E existe um segundo 
grupo majoritário, formado por $55,7 \%$ das famílias, com altíssima dependência onde o tabaco, que representa entre 75 a $100 \%$ do orçamento familiar. Esses dados transmitem a dimensão do grau de dependência das famílias do território Centro-Sul em relação ao cultivo de tabaco.

Porém, cabe salientar que essa não pode ser caracterizada como uma situação estanque, existe uma dinâmica social de reação a essa situação. Esse fato pode ser observado quando os agricultores são confrontados com a pergunta: A família tem interesse em sair da atividade do tabaco? Emerge a resposta, de forma surpreendente, que 65\% das famílias entrevistadas têm desejo de sair da dependência do tabaco. Esse é um comportamento não esperado que suscita a busca de raízes teóricas para uma melhor compreensão.

Segundo Ploeg (2008), a agricultura camponesa6 busca, por meio de processos de coprodução, a ampliação da qualidade de vida da família com projetos sociais que coadunam as bases ecológicas do ecossistema e as características sociais dos agricultores.

As estratégias de comercialização dos excedentes procuram mercados curtos e descentralizados, embebidos em relações sociais. Os atores retomam as ideias de diversificação de cultivos e criações, buscando uma base autossustentada de produção e, principalmente, constituem processos participativos de composição dos projetos sociais dentro das arenas de construção do conhecimento.

Para Ploeg (2008), é central para a família camponesa a ampliação da autonomia. Essa é buscada por meio da redução da dependência externa, por meio do processo coprodução com os elementos naturais, e da rearticulação com o tecido social onde são dialogadas, com os diversos atores, as informações para os projetos e são desenvolvidas as atividades do mercado.

Neste trabalho, é possível a constatar que o SIPT produz um processo de redução da autonomia em várias direções. Em um primeiro aspecto, quando a dependência do orçamento familiar fica altamente centrada em uma única fonte, sendo ela externa e de baixo controle da família, ou seja, um mercado autorregulado. Em outro aspecto, o tabaco

\footnotetext{
6 Esse trabalho toma como princípio a aproximação da noção de camponês e agricultor familiar. Entende-se o debate acadêmico sobre a disputa conceitual, mas para o escopo dessa análise entende-se que não cabe a ampliação dessa discussão teórica.
} 
utiliza um pacote moderno para o seu cultivo, no qual os insumos são externos, sendo fornecidos diretamente pela empresa fumageira, esse elemento impede a utilização de estratégias de coprodução. E, finalmente, a comercialização do tabaco é atrelada, sendo os valores de remuneração definidos distante do espaço social dos agricultores.

Nesse sentido, o cultivo de tabaco, apesar de ser fundamental economicamente para as famílias, pode ser entendido pelos atores como um processo de descampesinização (PLOEG, 2008), ou seja, um caminho onde os agricultores perdem elementos fundamentais da sua identidade de camponês. Essa tende a ser uma raiz teórica que auxilia o entendimento do desejo das famílias de saírem da atividade com o tabaco.

Cabe salientar, como citado anteriormente, o trabalho desenvolvido por Cotrim (2013), que apontou essa mesma tendência das famílias de agricultores que cultivam tabaco e abalizou que os fatores decisivos para esse comportamento foram o alto grau de penosidade do trabalho com o tabaco, em especial nas fases de colheita e secagem das folhas, que ocorrem durante o verão, e também o elemento da saúde das famílias, que é prejudicada pelo uso de vários agrotóxicos e o próprio contato com a nicotina pela absorção dérmica no manejo do cultivo.

Continuando a análise sobre a substituição do tabaco, entende-se que a concretização da troca do cultivo de tabaco pelas famílias é um percurso longo e não linear. No senso comum, é verbalizado pelos agricultores a busca de um "cultivo mágico" que possua o mesmo rendimento econômico do tabaco sem as desvantagens sociais e ambientais. No mundo real, isso não se materializou e a construção de uma alternativa para diversificação tende a passar pelo resgate de experiências vivenciadas pelos grupos sociais (LONG; LONG, 1992).

A experimentação de determinados cultivos e criações em pequenos espaços, a estruturação de mercados locais ou socialmente mediados e a retomada do processo de coprodução com a natureza são os princípios que se apresentam para a construção das alternativas de diversificação ao tabaco (COTRIM, 2013).

Foi identificado, na pesquisa, um espaço privilegiado de experimentação camponesa de produção para o autoconsumo familiar, que são as hortas ou quintais. No Gráfico 5 é possível a observação do comportamento desses dados. 
Décio Souza Cotrim, Mario Duarte Canever, Volnei Wrusch Leitzke 
Gráfico 5. Produção para o autoconsumo

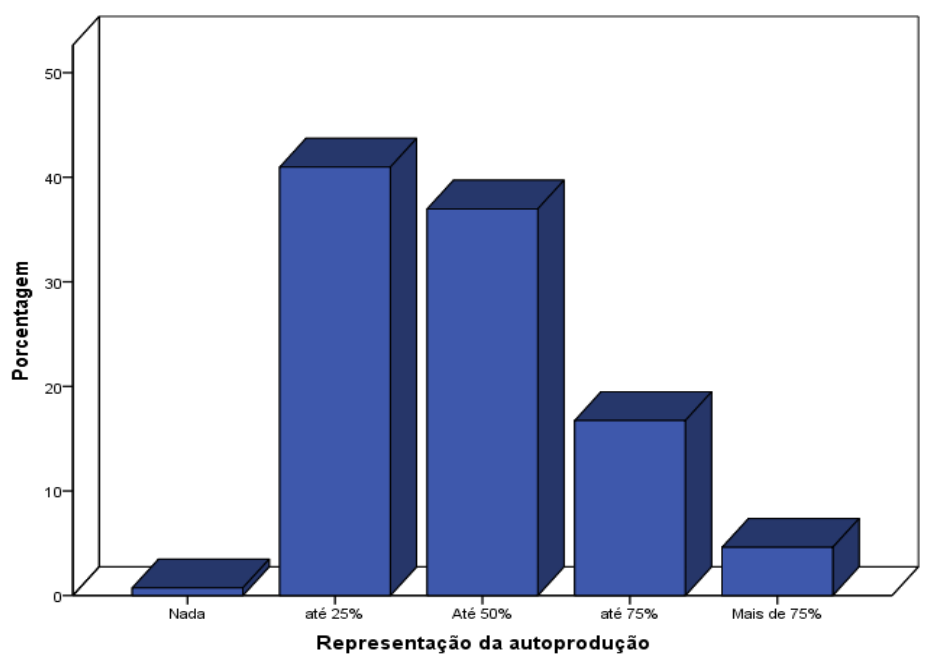

Fonte: elaborado pelos autores

A pergunta realizada na pesquisa indagou sobre o percentual da totalidade da alimentação familiar que era produzida na propriedade. Naturalmente, esses dados têm um alto grau de variação entre as famílias devido ao seu tamanho, hábito alimentar, preferências, entre outros. Porém, os dados indicam que entre $25 \%$ a $75 \%$ da alimentação das famílias é produzida dentro da propriedade, gerando um bom grau de segurança alimentar. Esse é um aspecto importante e que reforça a tese de um comportamento camponês dessas famílias (PLOEG, 2008).

Complementarmente, esses dados também expressam que existem muitos cultivos (mandioca, hortaliças, folhosas, citros, videiras, tubérculos, etc) e criações (aves, suínos, bovinos, peixes, etc) que são produzidos para autoconsumo e, consequentemente, experimentados e com possibilidade de diversificação ao tabaco.

Os agricultores constroem o conhecimento necessário ao desenvolvimento de determinado cultivo ou criação e, paulatinamente, vão ampliando sua área e volume de produção. Também experimentam os espaços de comercialização socialmente mediados como as feiras e os mercados institucionais que são locais de escoamento do excedente dessa produção. Esses tendem a ser elementos fundamentais na geração de insights na construção de processos de diversificação.

Porém, cabe a lembrança que essas famílias têm um grau de educação formal apenas fundamental. A construção dos sistemas de produção complexos que envolvem processos internos de coprodução e interfaces externas na conexão com os mercados socialmente mediados, 
possivelmente, exijam ferramentas inexistentes para muitos agricultores. Com certeza, esse não é um elemento que impede a transição, mas, possivelmente, imprimirá uma menor velocidade na diversificação, sendo um grande desafio aos assessores técnicos da equipe de extensão rural. 


\section{Conclusão}

O artigo aqui exibido tem como objetivo a apresentação da caracterização e análise dos elementos centrais da lógica da agricultura familiar que cultiva tabaco no território Centro-Sul do RS, pautada em uma amostra de 960 entrevistas. Porém, entende-se que é possível uma extrapolação, apontando pontos que caracterizam um conjunto maior de famílias de agricultores, possivelmente um ponto médio no sul do Brasil, em razão da amplitude da amostra analisada. Necessariamente, essa hipótese precisa ser validada por outros trabalhos.

Um dado destaque foi a determinação de que os agricultores familiares possuem a educação formal em nível fundamental, sendo que ensino superior ou ensino médio técnico não são realidades para esse grupo. Esse fato permite a prospecção de que esse grupo possui um ferramental mais operacional, que é compatível com a forma de atuação do SIPT. Por outro lado, possivelmente, haverá um maior grau de dificuldades na construção de novos sistemas de produção e insights para as novas estratégias de mercado devido à falta de ferramentas exercitadas em maiores níveis educacionais.

As famílias de agricultores familiares possuem um amplo tempo de convivência com o cultivo de tabaco, tendo, em média, 20 a 30 anos de experiências dentro do SIPT. Esse largo período levou a constituição de um conjunto de estruturas, como estufas de secagem, o que produz a tendência à ampliação da permanência das famílias nessa atividade.

$\mathrm{Na}$ organização do cultivo de tabaco, os agricultores plantam, em média, trinta mil plantas por safra, o que equivale a dois hectares. Uma estratégia desenvolvida pelo grupo é o aumento do plantio para $40 \mathrm{mil} \mathrm{a}$ $50 \mathrm{mil}$, dentro do mesmo contrato com a empresa fumageira. Esse fato causa um afunilamento no momento da secagem, quando esses lançam mão do uso de estufas antigas. Essa tática visa a atender ao contrato, tanto em quantidade como em qualidade e, ao mesmo tempo, abastecer o mercado dos atravessadores, buscando o acréscimo dos rendimentos nas safras com menores produções.

Finalizando, ficou expresso, neste artigo, que o SIPT gera um processo dentro das famílias de agricultores que limita a diversificação, tendo como principal razão o uso excessivo da mão de obra. Como resultado, foi diagnosticado que as famílias de agricultores possuem 
uma condição entre alta e altíssima dependência econômica do tabaco. Por outro lado, também ficou expressa a grande vontade das famílias (65\%) em abandonar o tabaco e buscar outras possibilidades de diversificação. Possivelmente, esse fato ocorre pelo rompimento dos princípios da condição camponesa das famílias.

\section{REFERÊNCIAS}

Asssociação dos Fumicultores do Brasil. Evolução da Fumicultura. 2014. Disponível em: <www.afubra.com.br>. Acesso em: 05 jan. 2016.

BONI, V.; QUARESMA, S.J. Aprendendo a entrevistar: como fazer entrevistas em ciências sociais. Revista Eletrônica de Pós-Graduação em Sociologia Política da UFSC, Florianópolis, v.2, n.1, p.3-10, jan./jul. 2005. Disponível em: <http://www.emtese.ufsc.br>. Acesso em: 01 fev. 2007.

BRASIL. CASA CIVIL. Lei 11.326 de 24 de julho de 2006: Política Nacional de Agricultura Familiar. Brasília, 2006.

BRASIL. Ministério do Desenvolvimento e Abastecimento. Plano Territorial de Desenvolvimento Rural Sustentável: Território Centro Sul. Brasília: MDA, 2009.

BRASIL. Ministério do Desenvolvimento Agrário. Ações do Ministério do Desenvolvimento Agrário para diversificação da produção e renda em áreas cultivadas com tabaco no Brasil. Brasília: MDA, 2010.

BRASIL. Ministério do Desenvolvimento Agrário. Chamada pública para seleção de entidade executora de assistência técnica e extensão rural para agricultores/as familiares inseridos em municípios com produção de tabaco na região sul do Brasil. 2013. Disponível em: <http://www.mda.gov.br/portalmda/sites/default/files/chamadas/CHA MADA_Diversifica\%C3\%A7\%C3\%A3o_SUL_republica\%C3\%A7\%C3\%A3o.pdf >. Acesso em: 06 maio 2015. 
COTRIM, D.S. O estudo da participação na interface dos atores na arena de construção do conhecimento agroecológico. 2013. Tese (Doutorado) - Programa de Pós-Graduação em Desenvolvimento Rural da Universidade Federal do Rio Grande do Sul. Porto Alegre, 2013.

GOHN, M. de G. Educação não-formal, participação da sociedade civil e estruturas colegiadas nas escolas. Ensaio: aval.pol.públ.Educ. [online]. 2006, vol.14, n.50, pp. 27-38. ISSN 0104-4036.

IBGE. Censo Agropecuário 2006. Rio de Janeiro. 2010. Disponível em: <http://www.ibge.gov.br>. Acesso em: 01 fev. 2011.

LONG, N.; LONG, A. Battlefields of Knowledge: the interlocking of theory and practice in social research and development. London: Routledge,1992, p.306.

OLIVEIRA, M. K. de. Jovens e Adultos como sujeitos de conhecimento e aprendizagem. In: FÁVERO, Osmar. Educação como exercício de diversidade. Brasília: Ministério Educação, 2007. p. 61-84. Disponível em:

$<$ http: / portal.mec.gov.br/index.php?option=com_docman\&view=down load\&alias=647-vol7div-pdf\&ltemid=30192 >. Acesso em: 19 jan. 2016.

OLIVEIRA, P.P.V. et al. Primeiro relato do surto da doença da folha verde do tabaco no Brasil. Cadernos de Saúde Pública[online]. vol. 26, n.12, p. 2263-2269, 2010. Disponível em: <http://dx.doi.org/10.1590/S0102$311 \times 2010001200005$ >. Acesso em: 19 fev. 2012.

PLOEG, J. D. van der. Camponeses e Impérios Alimentares: lutas por autonomia e sustentabilidade na era da globalização. Porto Alegre: Ed. da UFRGS, 2008.

ROSIAK, M. Dom Feliciano: 117 anos de imigração, história e cultura polonesa. Dom Feliciano: PM de Dom Feliciano, 2008.

VARGAS; OLIVEIRA. Agricultura Familiar e Estratégias de Diversificação: análise comparativa da viabilidade. In: ENCONTRO REGIONAL DE 
ECONOMIA, 8., 2010, Porto Alegre. Anais ... Porto Alegre: ANPECSUL, $2010 . \quad$ Disponível em: $<$ http://www.ppge.ufrgs.br/anpecsul2010/artigos/10.pdf $>$. Acesso em: 10 ago. 2011.

VERDEJO, M. E. Diagnóstico Rural Participativo: Guia Prático de DRP. Brasília: MDA-SAF-DATER, 2006.

Submetido em 20/05/2016

Aprovado em 27/07/2016

Sobre os autores

Décio Souza Cotrim

Professor Doutor da UFPEL-Faculdade de Agronomia Eliseu Maciel- Departamento de Ciências Sociais Agrárias.

E-mail: deciocotrim@yahoo.com.br

Mario Duarte Canever

Professor Doutor da UFPEL-Faculdade de Agronomia Eliseu Maciel- Departamento de Ciências Sociais Agrárias.

E-mail: mcanever@gmail.com

Volnei Wrusch Leitzke

Mestre em Ciências Solos. Extensionista Emater-RS.

E-mail: vleitzke@emater.tche.br 